\title{
Long-term Variations of the Baiu Frontal Zone and Midsummer Weather in Japan
}

\author{
By Naoki Sato and Masaaki Takahashi \\ Center for Climate System Research, University of Tokyo, Tokyo, Japan
}

(Manuscript received 11 May 1999, in revised form 2 February 2001)

\begin{abstract}
A comparison of midsummer (August 1 to 10) daily sunshine duration averaged over 10 years for the periods 1986 1995 and 1959 1968 indicates that it dropped by as much as $2 \mathrm{hr}^{-1}$ day $^{-1}$ in some observational sites in central Japan. The diurnal temperature range and water vapor pressure in midsummer also decreased. A long-term examination of the Baiu frontal zone location suggests that its slower northward movement in recent years affected the midsummer weather. Furthermore, the sea level pressure increased in northern Japan, while the equivalent potential temperature in the lower atmosphere dropped in central Japan. The change in the northward movement of the Baiu frontal zone is likely to be associated with the strengthening of the polar airmass around Japan.
\end{abstract}

\section{Introduction}

The Baiu is the rainy season associated with the Baiu front, and is seen in most parts of Japan. In central Japan, it usually starts in June and ends in July (cf., Yoshino 1978).

With respect to the frontal zones over East Asia in summer, the Pacific Polar frontal zone, the Eurasian Polar frontal zone, and the Siberian-Canadian Arctic frontal zone can be identified (e.g., Matsumoto 1985). The Baiu frontal zone is regarded as the western part of the Pacific Polar frontal zone generated along the boundary between the maritime tropical airmass and the maritime polar airmass (cf., Yoshimura 1967; Akiyama 1973), although some authors regard it as the subtropical frontal zone in the northern hemisphere (e.g., Ninomiya et al. 1980; Ninomiya 1984). A subtropical anticyclone is dominant over the North Pacific in summer, and warm and moist air of the maritime tropical airmass is supplied to the front along the

Corresponding author: Naoki Sato, Center for Climate System Research, University of Tokyo 4-6-1 Komaba, Meguro-ku, Tokyo 153-8904, Japan.

E-mail: naoki@ccsr.u-tokyo.ac.jp

(C)2001, Meteorological Society of Japan northwest vicinity of the subtropical anticyclone (cf., Akiyama 1973; Matsumoto 1985). During the Baiu season, the Baiu frontal zone is situated over Japan, and gradually moves northward, in association with the westward extension of the Pacific anticyclone. By the end of July, the frontal zone reaches the northern part of Japan, and becomes inactive. This means the end of the Baiu, which is followed by the midsummer season in Japan (cf., Yoshimura 1967; Akiyama 1973; Matsumoto 1985).

The end of the Baiu, determined by the Japan Meteorological Agency (JMA), was later in the 1980 s and the early 1990s compared with that in the 1950 s to 1970 s (cf., JMA 1997). Yamakawa (1988) also showed that the end of the Baiu season and the start of the midsummer season have become later in recent years, associated with more frequent appearances of the front over Japan in late July. Long-term evolution of the Baiu frontal zone has not yet been investigated in detail since Yamakawa (1988), although numerous authors have studied the climatological characteristics of the frontal zone itself (e.g., Yoshino 1965, 1966). The propagation of seasons can also be characterized by the sunshine duration and cloud amount (e.g., Maejima 1967; Kawamura 1973). However, long- 
term changes in the sunshine duration and cloud amount in Japan have not been examined yet. Furthermore, Sakaida (1977) demonstrated that the variation of August temperature is related to the frontal distribution. Nishimori (1997) examined the variation of summer temperature and precipitation in Japan in the past 100 years, and pointed out some characteristics of interannual and longterm changes. According to Nishimori (1997), no clear long-term trends are detected in both temperature and precipitation in summer since 1960.

In the present study, long-term changes in weather conditions in midsummer following the Baiu from the 1960 s to the middle 1990 s are assessed by analyzing data of sunshine duration and other data in Section 2. In Sections 3 and 4, modification in the northward movement of the Baiu frontal zone and that in sea level pressure (SLP) are examined in order to understand the mechanism of the cloudy or rainy midsummer weather. Conclusions are presented in Section 5.

\section{Weather conditions in midsummer}

Surface Daily Product (SDP) data by the JMA are used for detecting long-term variations of midsummer (late July and early August) weather. Data of sea level pressure (SLP), daily mean temperature, daily maximum/minimum temperature, water vapor pressure, sunshine duration, cloud amount, and precipitation are analyzed here. Data are available at 155 observational sites. Daily mean values of sea level pressure, temperature, and water vapor pressure are obtained from hourly observations, while daily mean cloud amounts are calculated from observations performed 2, 3 or 4 times a day. In the present study, data from 1959 to 1995 are analyzed.

\subsection{Sunshine duration and cloud amount}

Long-term changes in daily sunshine duration for the periods July 21 to 31 , and August 1 to 10 are examined. In 1986 or 1987, the JMA replaced the Jordan sunshine recorders with the rotating mirror sunshine recorders. Referring to Katsuyama (1987), the observed values before the replacement are calibrated as

$$
S_{R}= \begin{cases}0.8 S_{J} & \left(S_{J}<2.5\left[\mathrm{hr} \mathrm{day}^{-1}\right]\right) \\ S_{J}-0.5\left[\mathrm{hr} \mathrm{day}^{-1}\right] & \left(S_{J} \geq 2.5\left[\mathrm{hr} \text { day }^{-1}\right]\right)\end{cases}
$$

where $S_{J}$ is the observed value of daily sunshine duration obtained by the Jordan sunshine recorder before the replacement, and $S_{R}$ is the calibrated value corresponding to the rotating mirror sunshine recorder. This relation was determined based on the results of observational comparisons between the two sunshine recorders.

Figure 1 indicates the name of areas and the location of some of the observational sites in Japan referred in the followings. Figure 2 shows the time evolution of sunshine duration for the period $\mathrm{Au}$ gust 1 to 10 at Toyama in the Hokuriku area (the continental side of central Japan), where a significant decrease is found. In order to reduce the interannual variation caused by El Niño (cf., Miyazaki 1989) and other interannual oscillation, 7-year running mean values are also shown (thick line). A gradual decrease in sunshine duration is found. Similar decreases can be seen at the other sites in the Hokuriku area and San'in area (the continental side of western Japan). In the southern part of the Tohoku area (the northeastern part of the main island), the sunshine duration slightly increased before the 1970s, and then it greatly decreased (not shown). Note that an 11-year period oscillation can be detected in Fig. 2. However, this oscillation is

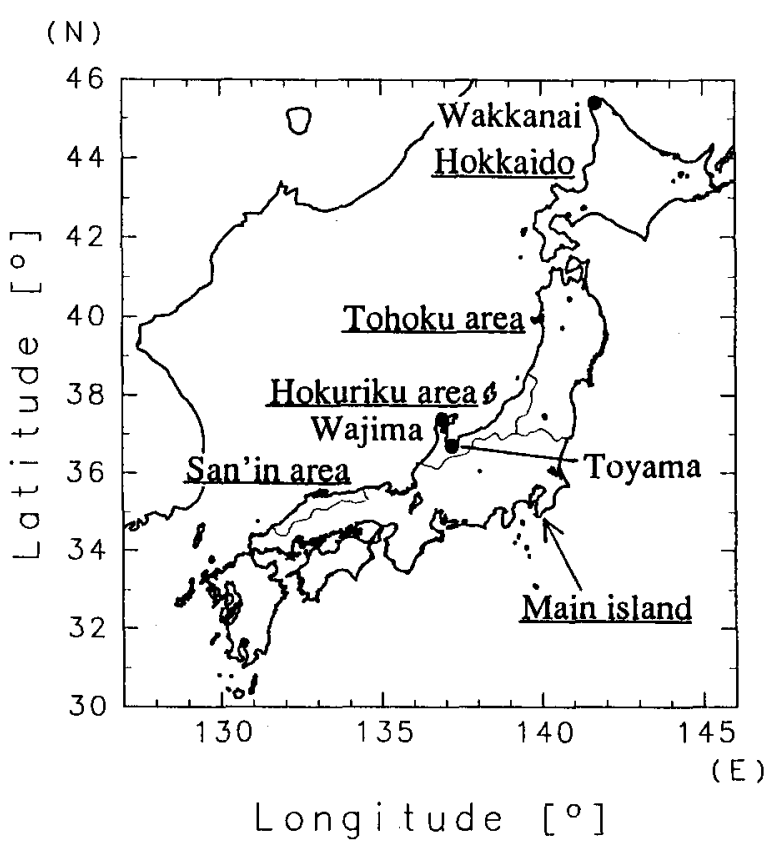

Fig. 1. Location of the observational sites in Japan selected for examining the temporal changes. The names of the areas are underlined. 


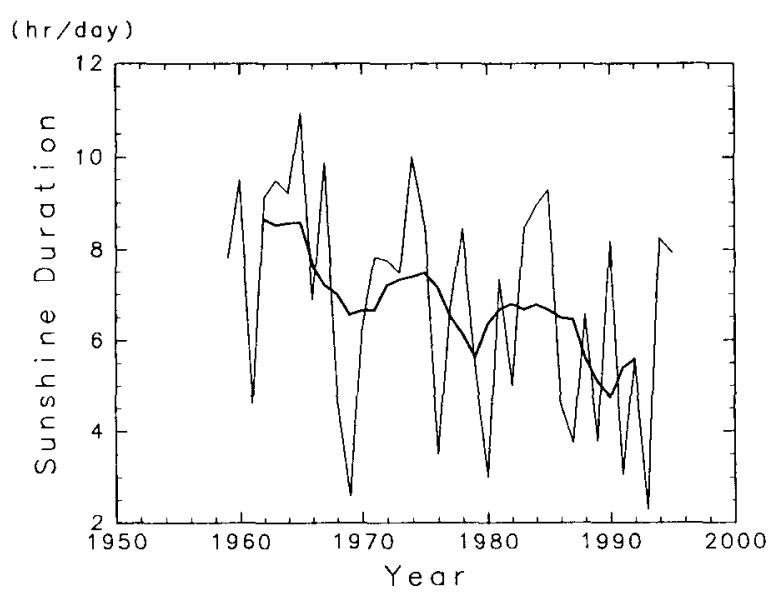

Fig. 2. Temporal variation in daily sunshine duration for the period August 1 to 10 at Toyama (thin line). 7-year running mean values are also shown (thick line).

not in the scope of the present paper.

In order to discuss the long-term tendencies in sunshine duration all over Japan, the differences between the averages for years 1959 1968 (previous decade) and those for 1986 1995 (recent decade) were calculated. Values averaged over 10 years are used here in order to reduce interannual and decadal variations. Figure 3 shows the difference between both decades for the period August 1 to 10. The sunshine durations decreased in most parts of Japan, except in Hokkaido in northern Japan. The decrease at some observational sites exceeds $2 \mathrm{hr}$ day $^{-1}$. The results of the $t$-test with respect to the differences show that the decreases at most of the sites in the Hokuriku area and the southern part of the Tohoku area are statistically significant with a significant level of $95 \%$. The difference of sunshine duration for the period July 21 to 31 has the same tendency as that for August 1 to 10 . However, the tendencies seen in Figs. 2 and 3 are not detected for the other periods of the year. Figure 4 shows the seasonal variation of daily sunshine duration from June to August at Toyama averaged for years 1959 1968 (thin line) and for 1986 1995 (thick line), respectively. In both decades, the sunshine duration is shorter during the Baiu, and it increases in late July, corresponding to the ending of the Baiu. Comparing the results for the recent decade with those for the previous one, it can be understood that the sunshine duration decreased both during the Baiu and midsummer, especially in early August.

Figure 5 shows the temporal variation in cloud amount analyzed in the same manner as that for

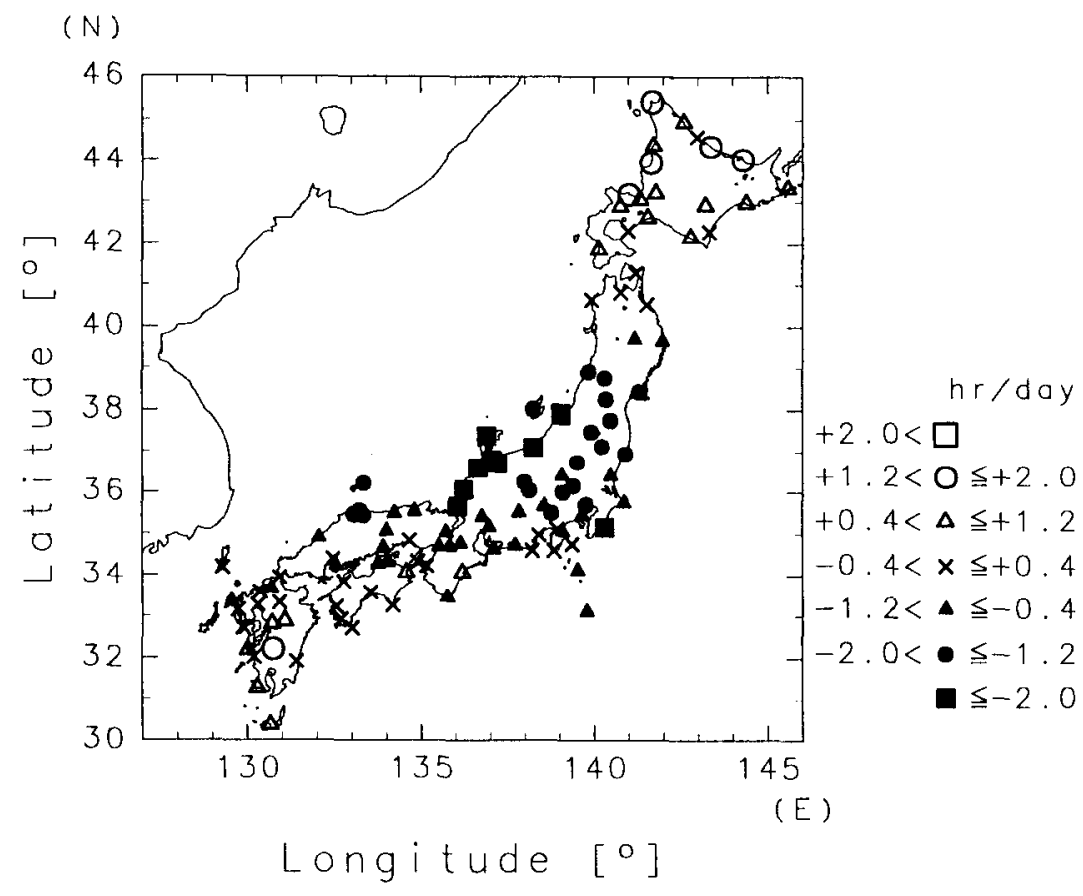

Fig. 3. Change in daily sunshine duration for the period August 1 to 10 between the years 1959 to 1968 and years 1986 to 1995 . A positive value means an increase in sunshine duration. 


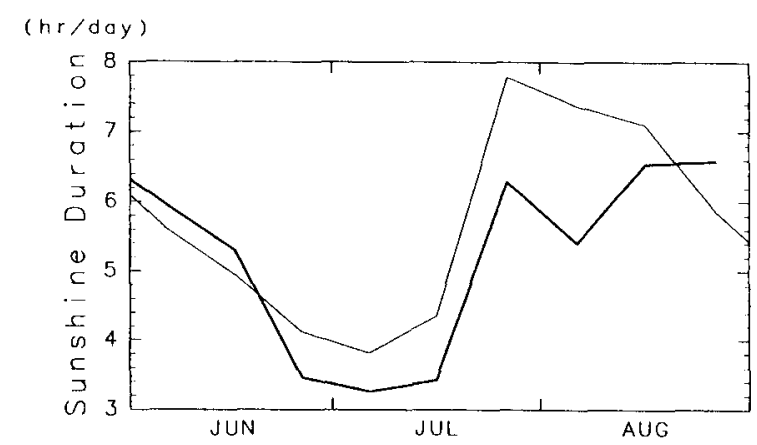

Fig. 4. Temporal variation in 10-day mean daily sunshine duration from June to August at Toyama. The averages for years 1959 1968 (thin line), and those for 1986 1995 (thick line) are shown.

the sunshine duration in Fig. 3. The cloud amount clearly increased in the southern part of the Tohoku area, the Hokuriku area, and the San'in area, corresponding to the shortening in sunshine duration. Significant negative correlations can be seen between the changes in cloud amount and those in sunshine duration. Further, the temporal changes in cloud amount also correspond well to those in sunshine duration shown in Fig. 2 (not shown). The sunshine duration dropped as the cloud amount increased.

Precipitation is also examined in the same manner. However, no correlation is found between the variation in precipitation and that in sunshine duration or cloud amount. This is probably because the total amount of precipitation can strongly be affected by certain heavy rainfall events, such as typhoons or local heavy rainfalls.

\subsection{Temperature and water vapor pressure}

The seasonal march can be discussed by analyzing the variation of the temperature and water vapor pressure (e.g., Maejima 1967). Further, airmasses in midsummer can be identified according to the distributions of temperature and water vapor pressure (e.g., Akiyama 1973; Matsumoto 1984). The long-term variation of the temperature is examined, corresponding to those in sunshine duration and cloud amount. Firstly, the change in daily mean temperature for the period August 1 to 10 is examined in the same manner as in the previous subsection. However, the spatial distribution of long-term change is not clear (not shown). Secondly, the change in diurnal temperature range (the difference between the maximum and minimum temperatures) is investigated

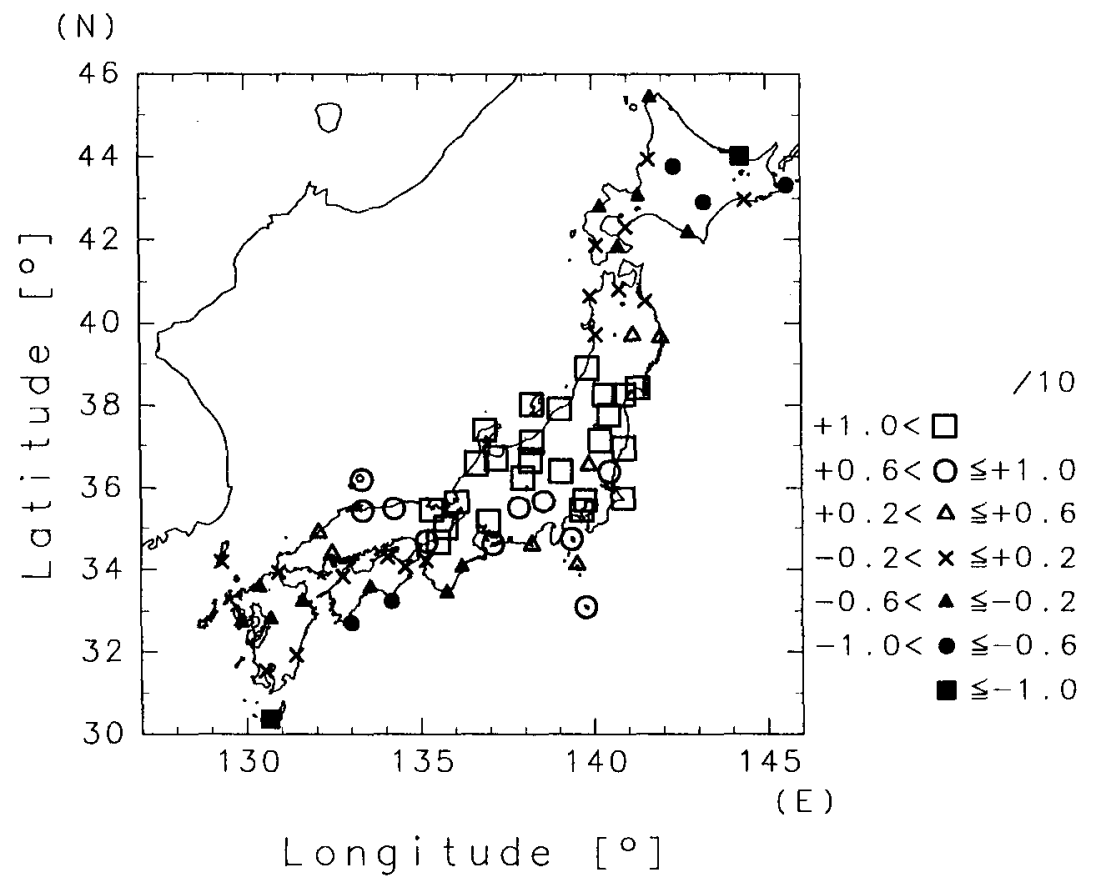

Fig. 5. The same as in Fig. 3, except for cloud amount. 




Fig. 6. The same as in Fig. 3, except for diurnal temperature range,

as shown in Figs. 6 and 7. The temperature range decreased in the regions where the sunshine duration shortened and the cloud amount increased. The decrease at some sites exceeds $2{ }^{\circ} \mathrm{C}$. The pattern of the temporal change in the diurnal temperature range at Toyama in Fig. 7 is similar to that of the sunshine duration (Fig. 2). The decrease in temperature range is accompanied by the increase in cloud amount which causes a screening of inso-



Fig. 7. The same as in Fig. 2, except for diurnal temperature range. lation and radiative cooling.

The variation in water vapor pressure is also analyzed in Fig. 8. Note that the average of water vapor pressure for years 1961 1970 was used instead of that for the years $1959 \sim 1968$, because the 10-day mean values of water vapor pressure are not available before 1960 . The water vapor pressure decreased in central and western Japan. No clear correlations are found between its variation and that of the sunshine duration.

Cloud activity and precipitation along the Baiu front are maintained by the supply of hot and moist air (cf., Ninomiya 1980). On the other hand, the temperature and water vapor pressure are higher in midsummer than in the Baiu (cf., Maejima 1967). In the present analysis, the increase in cloud amount is not accompanied by an increase in the mean temperature or water vapor pressure. The changes in cloud amount may be due to a delayed seasonal march rather than a supply of airmasses with higher temperature and humidity from the south.

\section{Behavior of the Baiu frontal zone}

Precipitation and convective activities in East Asia in early summer are closely related to the Baiu front (e.g., Yamakawa 1988; Matsumoto 1992; Kato 1997). Therefore, changes in the Baiu frontal 


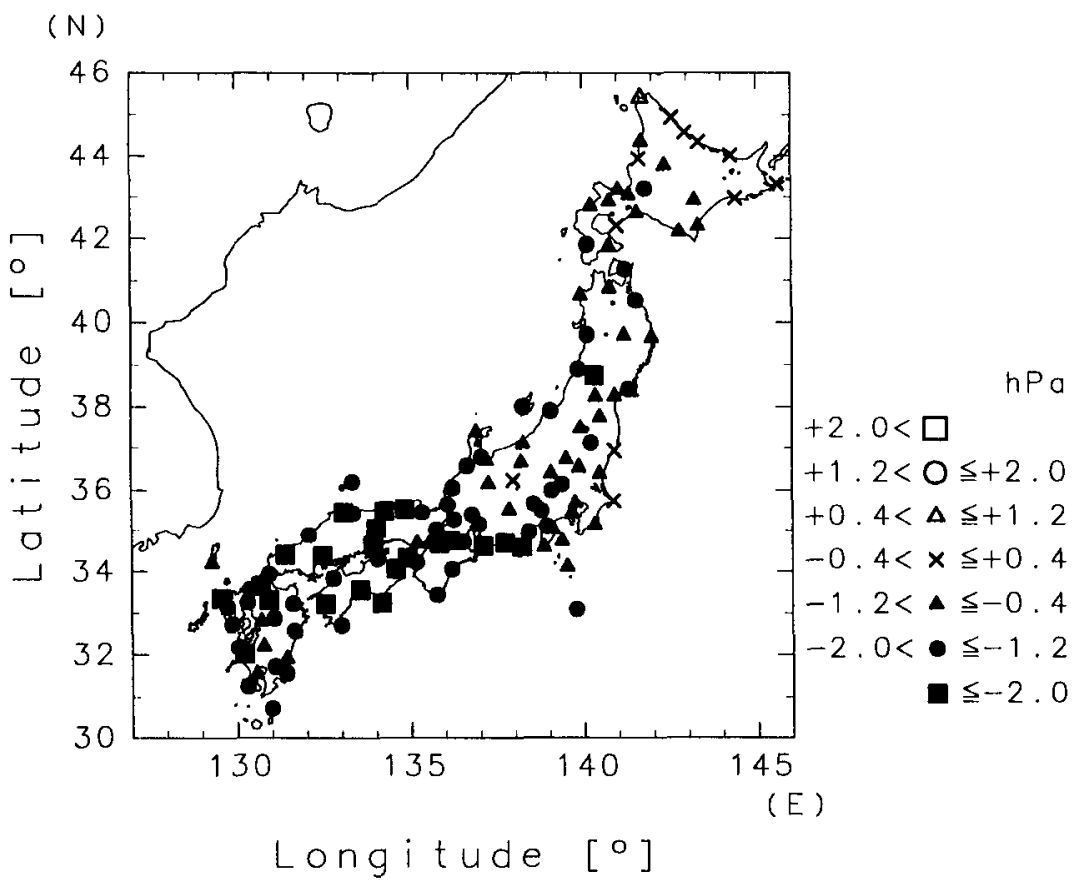

Fig. 8. Change in water vapor pressure for the period August 1 to 10 between the years $1961 \sim 1970$ and years 1986 1995.

zone may alter the summer weather conditions in central Japan as discussed in Section 2.

\subsection{Location of fronts on the weather chart}

Long-term variation of the behavior of the Baiu frontal zone is examined. Firstly, the location of fronts is read on the daily surface weather charts at 1200 UTC by the JMA from June 1 to August 10 for the period 1959 to 1995 . Here, the values of the latitudes at the intersections of the front and the longitudes of $110^{\circ}, 120^{\circ}, 130^{\circ}, 140^{\circ}$, and $150^{\circ} \mathrm{E}$ are obtained. The kind of front such as stationary front, warm front, cold front, or occluded front is not considered here. Since the most southerly frontal zone over East Asia is the Baiu frontal zone (cf., Matsumoto 1985), the value for the most southerly intersection is used, if there are more than one intersection for each longitude line. According to Yoshimura (1967) and Matsumoto (1985), the Baiu frontal zone as the Pacific Polar frontal zone is usually located south of $50^{\circ} \mathrm{N}$. Therefore, the fronts higher than $50^{\circ} \mathrm{N}$ are neglected. Then, the mean values of the latitudes are calculated for each 10-day period. In the present study, the values are respectively averaged for the same decades as discussed in Section 2. Note that there are no distinct and objective criteria for the front analyses (cf., Matsumoto 1985). However, modifications of the analytical method are not considered here.

Figures 9 and 10 show the mean location of the Baiu frontal zone for years 1959 1968 and for 1986 1995, respectively. In Fig. 9, it is located far south $\left(\sim 27^{\circ} \mathrm{N}\right)$ of the main island of Japan at the beginning of June. During the Baiu, it continues to move northward. By the beginning of August, it has moved north of the Tohoku area. In Fig. 10, on the other hand, the frontal zone is located rather north $\left(\sim 30^{\circ} \mathrm{N}\right)$ at the beginning of the Baiu. However, the northward movement for the recent decade is slower than that for the previous decade during the Baiu season. The frontal zone is still located near central Japan even at the beginning of August. The tendency shown here is consistent with more frequent appearances of fronts over Japan in recent years, demonstrated by Yamakawa (1988). The changes in the midsummer weather in Japan were caused by those in the behavior of the Baiu frontal zone. Note here that its location at the beginning of the Baiu is rather north in the recent decade. However, changes seen in the early Baiu are not the scope of the present paper. 


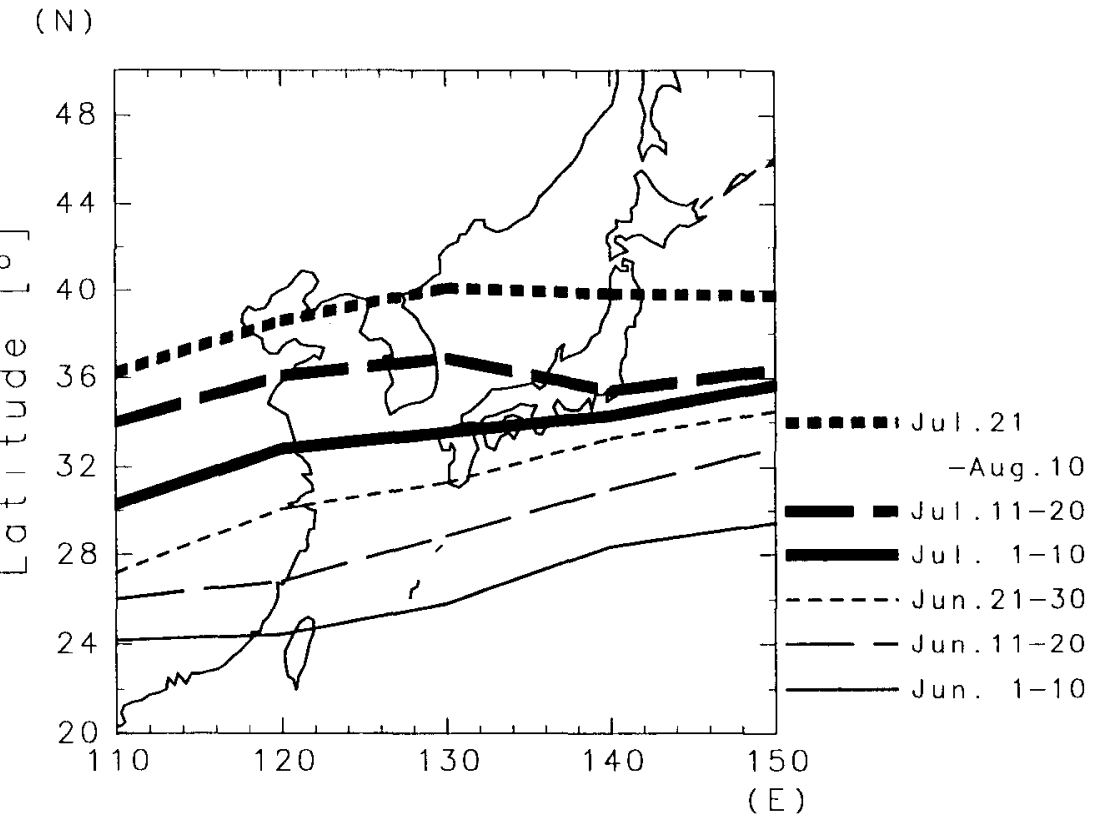

Longitude $\left[^{\circ}\right]$

Fig. 9. The mean location of the Baiu front for every 10-day period (June 1 to August 10) averaged over the years $1959 \sim 1968$.

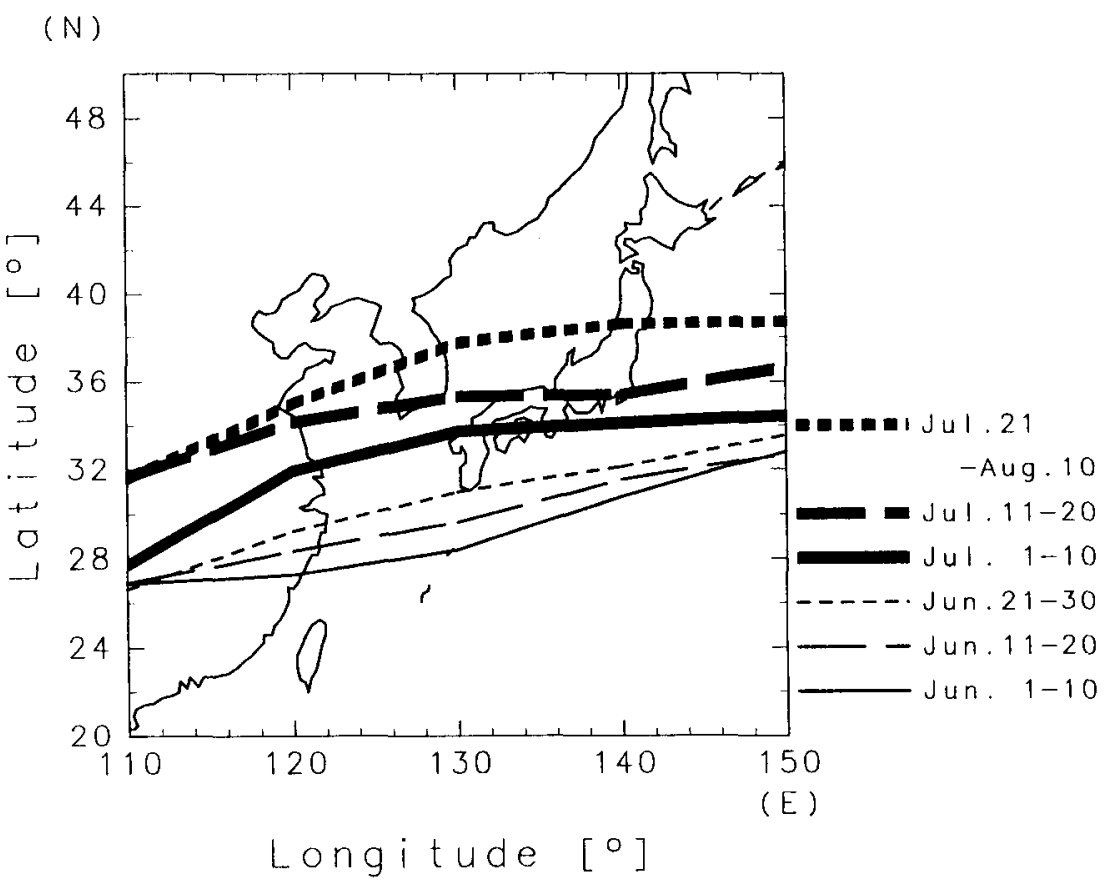

Fig. 10. The same as in Fig. 9, except for the years 1986 1995. 


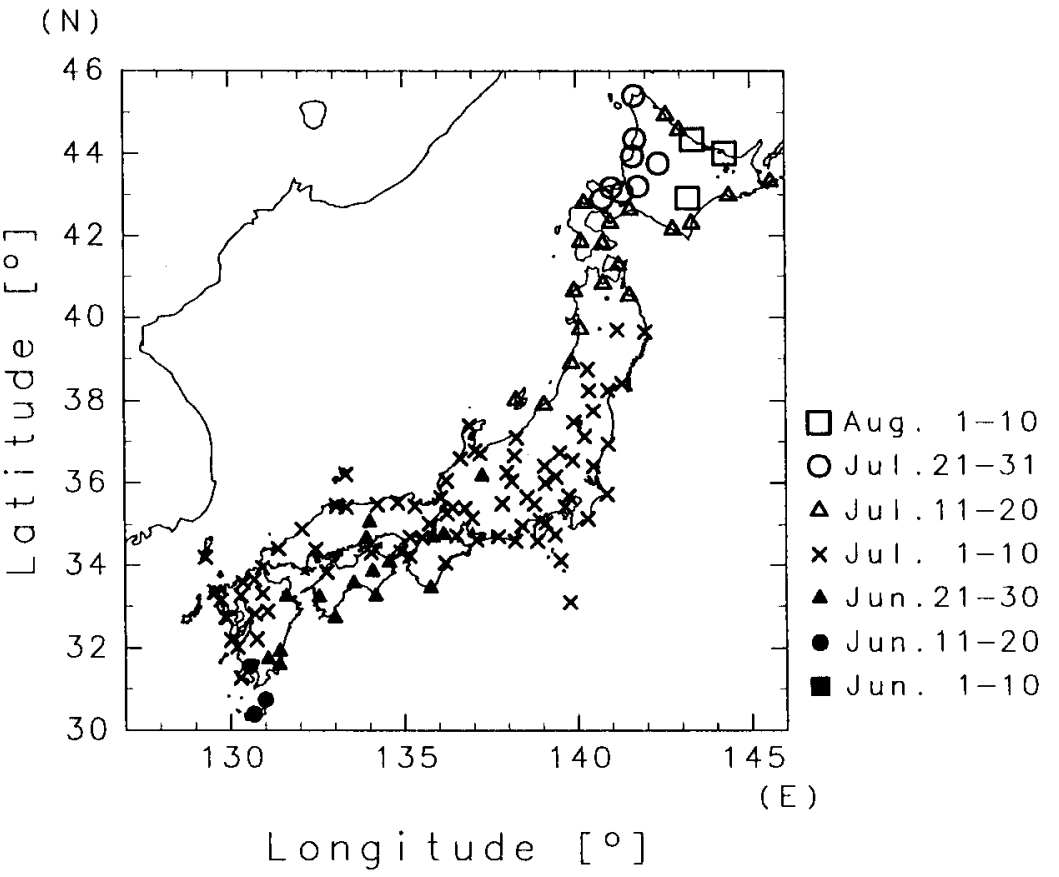

Fig. 11. The appearance of the cloud amount maximum for the years 1961 1970.

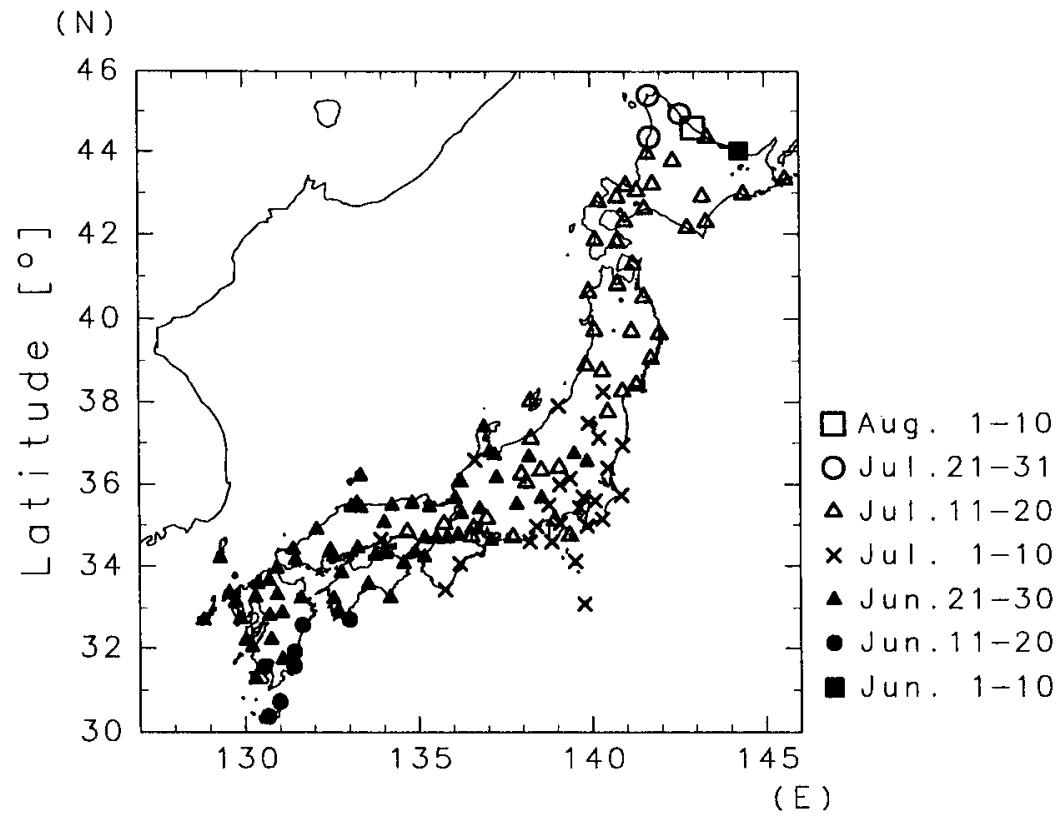

Longitude $\left[{ }^{\circ}\right]$

Fig. 12. The same as in Fig. 11, except for the years 1986 1995. 


\subsection{Shifts of the appearances of the precipitation and cloud amount maxima}

In this subsection, the results in the previous subsection are confirmed, by analyzing other meteorological elements such as the shift of the appearance of the cloud amount and precipitation maxima.

Yoshino (1966) determined the period when the precipitation at each site reaches its maximum, with respect to some sites in and around Japan. He showed that the appearance of the precipitation maximum shifts from south to north, corresponding to the northward movement of the Baiu frontal zone. Therefore, in the present study, the appearance of the precipitation maximum at each site is analyzed for every 10-day period from June 1 to August 10. However, the northward shift of the precipitation maximum can not be detected. It is probably because the number of years is not sufficient.

According to Akiyama (1973), the northward movement of the Baiu front can be characterized, not only by the change in the distribution of precipitation, but also by that of cloud amount. Thus, similar analyses with respect to the maximum of cloud amount are performed. Figures 11 and 12 show the appearance of the maximum of cloud amount for the two decades, respectively. In both figures, the northward shift can be seen. In Fig. 11, most of the sites in the main island undergo the cloud amount maxima during or before the period July 1 to 10 . In Fig. 12, on the other hand, the maxima appear during or after the period July 11 to 20 in some sites in the northeastern and central parts of the main island. Furthermore, these maxima appear earlier in the recent decade than those in the previous decade in western Japan. These results are consistent with the slower northward movement of the frontal zone in the recent decade.

\section{Sea level pressure}

The behavior of the Baiu frontal zone may be affected by changes in the strength of the polar airmass and the tropical airmass, because the Baiu front can be regarded as the boundary of the two airmasses (cf., Matsumoto 1985). In order to understand the behavior of the Baiu frontal zone and the midsummer weather, long-term variations in SLP for the period August 1 to 10 are examined in the same manner as in Section 2. Figure 13 shows the difference between the averaged SLPs for years 1959 1968 and those for 1986 1995 during that period of the year. The SLPs are higher in northern Japan in recent years. The increase is greater than $1.5 \mathrm{hPa}$ in Hokkaido. A similar tendency can also

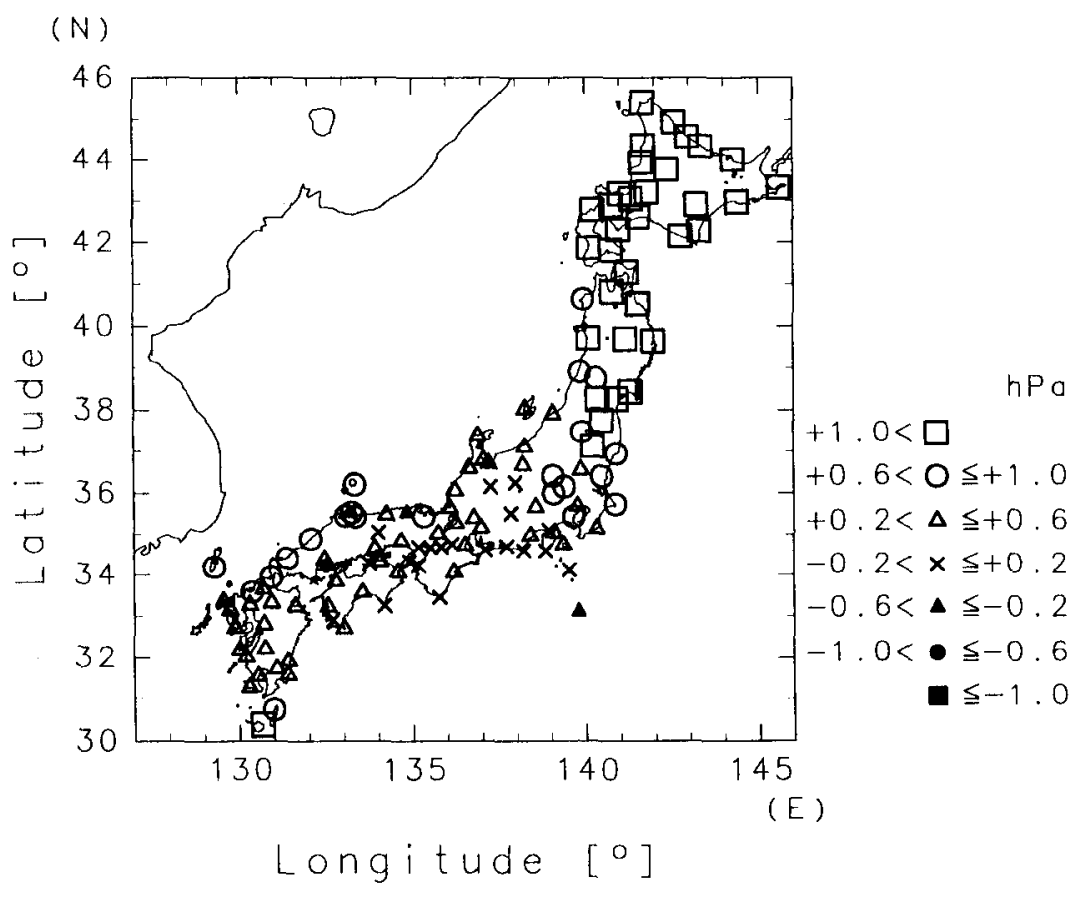

Fig. 13. The same as in Fig. 3, except for SLP. 




Fig. 14. 7-year running mean values of SLP at Wakkanai (thin line) and Toyama (thick line) for the period August 1 to 10.

be found for the period July 21 to 31 (not shown). However, it cannot be detected in other periods during the Baiu and midsummer. Figure 14 shows the 7-year running mean values of SLP at Toyama (thick line) and Wakkanai (thin line) (Fig. 1 for location). The decadal oscillations are rather significant, and the long-term trend is not clear at Toyama. On the other hand, a significant increase can be seen at Wakkanai. The temporal change in the SLP difference between Wakkanai and Toyama



Fig. 15. Temporal variation in SLP difference between Wakkanai and Toyama for the period August 1 to 10 (thin line). A positive value indicates a higher SLP at Wakkanai. 7-year running mean values are also shown (thick line). is illustrated in Fig. 15. Here, no decadal oscillations can be seen. The SLP at Wakkanai has increased since the late 1970s. The long-term variation in the midsummer weather is closely related to that in the SLP difference.

The changes in SLP may reflect those in the strength of the polar and tropical airmasses. The polar and tropical airmasses are identified by the equivalent potential temperature at $850 \mathrm{hPa}$. For example, Akiyama (1973) and Ninomiya et al. (1980) considered the airmass with an equivalent potential temperature lower than $320 \mathrm{~K}$ as the polar airmass, the one with an equivalent potential temperature higher than $330 \mathrm{~K}$ as the tropical airmass, and the one higher than $340 \mathrm{~K}$ as the modified tropical or monsoon airmass. Further, Matsumoto (1985) defined the warm sector of the Pacific Polar frontal zone as warm moist air with an equivalent potential temperature higher than 340 $\mathrm{K}$.

In order to investigate the change in the polar airmass, the evolution in $850 \mathrm{hPa}$ equivalent potential temperature at Wajima (Fig. 1 for location) near Toyama is examined as shown in Fig. 16 by utilizing data in Aerological Data of Japan (1959 1995) by the JMA. Data observed at 0900 LST are analyzed here. The equivalent potential temperature decreased in the 1970s and 1980s. A similar decrease can also be seen at Wakkanai (not shown). The long-term variation is similar to that for the SLP to a certain degree. Both the increase in SLP in northern Japan and the decrease in equivalent potential temperature reflect the strengthening of

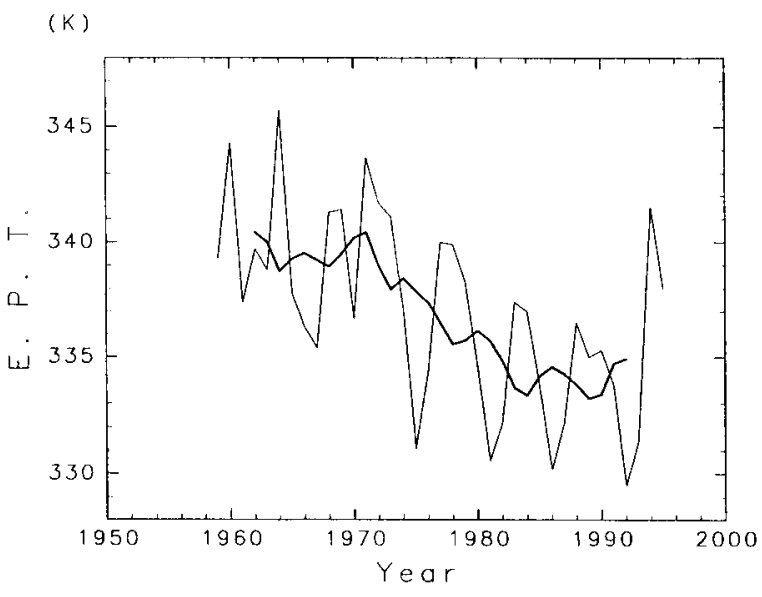

Fig. 16. The same as in Fig. 2, except for equivalent potential temperature at 850 $\mathrm{hPa}$ at Wajima. 
the polar airmass.

From these analyses, it is demonstrated that the polar airmass around Japan is stronger in the 1980s and 1990s compared with that in the 1960s. The result may explain the delayed northward movement of the Baiu frontal zone presented by Yamakawa (1988) and in the present study. The strengthened polar airmass seems to impede the northward movement of the Baiu frontal zone in the recent decade.

\section{Conclusions}

Long-term changes in midsummer weather in Japan were examined for the 1960 s to the middle 1990s. In central Japan, the cloud amounts are higher in the recent decade (1986 1995), in comparison with those in the previous one (1959 1968). The sunshine duration significantly dropped, in association with the increase in cloud amount. The decrease is as large as $2 \mathrm{hr} \mathrm{day}^{-1}$ in the southern part of the Tohoku, Hokuriku, and San'in areas.

The change in the behavior of the Baiu frontal zone reveals that its northward movement during the Baiu became slower in the recent decade than in the previous one. The alteration in midsummer weather mentioned above is probably caused by the slower northward movement of the Baiu frontal zone.

Furthermore, it was shown that the SLP increased in northern Japan and the equivalent potential temperature decreased in central and northern Japan, implying that the polar airmass around Japan became stronger. The stronger polar airmass seems to delay the northward movement of the Baiu frontal zone. The changes in the Baiu frontal zone and the midsummer weather are caused by the strengthening of the polar airmass.

The physical mechanism of the strengthening of the polar airmass is still unknown. Global climate changes may be able to explain it, since the distribution of the airmasses and the frontal zones has a large-scale structure. Further studies are required to understand the causes of the strengthening of the polar airmass.

\section{Acknowledgments}

The GFD-DENNOU Library was utilized for drawing the figures.

\section{References}

Akiyama, T., 1973: The large-scale aspects of the characteristic features of the Baiu front. Pap. Met. Geophys., 24, 157-188.

Japan Meteorological Agency, 1997: Kisho Nenkan 1997. Printing Bureau, Ministry of Finance, 273 pp (in Japanese).

Kato, K., 1997: A role of the Asian Monsoon system on the rainfall climatology during warm season in Japan. Kankyo Seigyo, 19, 5-20 (in Japanese with English abstract).

Katsuyama, M., 1987: On comparison between rotating mirror sunshine recorders and Jordan sunshine recorders. Weather Service Bulletin, 54, 169-183 (in Japanese).

Kawamura, T., 1973: Natural seasons in Monsoon Asia, in Yoshino, M.M. (ed.), Water Resources in Monsoon Asia. Kokin Shoin, 227-244 (in Japanese).

Maejima, I., 1967: Natural seasons and weather singularities in Japan. Geogr. Rep. Tokyo Metrop. Univ., 2, 77-103.

Matsumoto, J., 1985: Precipitation distribution and frontal zones over east Asia in the summer of 1979. Bull. Dept. Geogr. Univ. Tokyo, 17, 45-61.

___ 1992: The seasonal changes in Asian and Australian monsoon regions. J. Meteor. Soc. Japan, 70, 257-273.

Miyazaki, Y., 1989: Characteristics of the weather over Japan in El Niño years. Tenki, 36, 489-498 (in Japanese).

Ninomiya, K. and T. Akiyama, 1980: The Baiu frontal zone over east Asia. Kisho Kenkyu Note, 138, 1-29 (in Japanese).

_ , 1984: Characteristics of Baiu front as a predominant subtropical front in the summer Northern Hemisphere. J. Meteor. Soc. Japan, 62, 880894.

Nishimori, M., 1997: Variations of summer temperature in Japan and the cool and hot summer in 1993 and 1994. Kisho Kenkyu Note, 189, 199216 (in Japanese).

Sakaida, K., 1977: Regionality of the fluctuation of August air temperature in relation to the distribution of fronts in and around Japan. $A n$ nals. Tohoku Geogr. Assoc., 29, 92-100 (in Japanese with English abstract).

Yamakawa, S., 1988: Climatic variations in recent years from the viewpoint of the seasonal transition of prevailing pressure pattern types over east Asia. Geogr. Rev. Japan, 61, 381-403 (in Japanese with English abstract).

Yoshimura, M., 1967: Annual change in the frontal zones in the Northern Hemisphere. Geogr. Rev. Japan, 40, 393-408 (in Japanese with English abstract). 
Yoshino, M.M., 1965: Four stages of the rainy season in early summer over east Asia (Part I). J. Meteor. Soc. Japan, 43, 231-245.

, 1966: Four stages of the rainy season in early summer over east Asia (Part II). J. Meteor. Soc. Japan, 44, 209-217.

, 1978: Climatology. Taimeido, 90-97 (in Japanese). 